\title{
Factors Underlying Low Achievement of Saudi EFL Learners
}

\author{
Fakieh Alrabai $^{1}$ \\ ${ }^{1}$ Faculty of Arts, King Khalid University, Abha, Saudi Arabia \\ Correspondence: Fakieh Alrabai, Faculty of Arts, King Khalid University, Abha, Saudi Arabia. E-mail: \\ falrabei@kku.edu.sa
}

Received: March 7, 2016

Accepted: March 27, 2016 Online Published: May 25, 2016

doi:10.5539/ijel.v6n3p21

URL: http://dx.doi.org/10.5539/ijel.v6n3p21

\begin{abstract}
This paper is devoted to examining the factors responsible for the low achievement in English as a foreign language (EFL) among Saudi students. While some of these factors are demographic variables that pertain specifically to the learners themselves, such as gender, age, motivation, attitudes, aptitude, anxiety, autonomy, learning strategies, and learning style, most are external and outside the learners' control. These external factors are particularly represented by sociocultural factors, such as the influence of Arabic as the first language (L1); religion, culture, and society; instructional variables, such as teacher behavior and teaching styles, the curriculum, and the teaching methods; and finally, problems with the educational system in Saudi Arabia, such as overcrowded classes, lack of teacher training, and a lack of technology. This paper begins by emphasizing the importance of English language learning for Saudis, followed by an analysis and a discussion of the factors that might explain their lack of achievement. The paper concludes by presenting some implications and offering recommendations for EFL practitioners and policymakers in the Kingdom of Saudi Arabia (KSA) to address the factors contributing to low EFL achievement among Saudi learners.
\end{abstract}

Keywords: EFL learner, EFL teacher, teaching methods, EFL curriculum, achievement, Saudi Arabia

\section{Background}

Saudi EFL learners have often been described as having generally low achievement in English as a foreign language (EFL) (Al-Khairy, 2013a; Alrabai, 2014a; Alrahaili, 2013; Alrashidi \& Phan, 2015; Elyas \& Picard, 2010; Rahman \& Alhaisoni, 2013; etc.). Despite the enormous efforts of the Saudi government to improve English teaching and learning in the country, students' English proficiency remains unsatisfactory and far below expectations (see e.g., Alhawsawi, 2013; Al-Johani, 2009; Khan, 2011; Rajab, 2013). According to the statistics released in the third edition of The Official Guide to the TOEFL Test (2009), the average TOEFL result in Saudi Arabia is 57 out of 120, which is the second lowest in the entire Middle East and among the lowest average TOEFL scores in the world. The low competence in EFL among Saudi learners can be attributed to a variety of multidimensional factors. This paper will shed light on some of the factors that contribute to this phenomenon and will present suggestions for addressing each factor to overcome these barriers and improve EFL learning outcomes in the Saudi context.

\section{The Importance of English in Saudi Arabia}

Since its introduction in the Saudi educational system in the late 1920s (e.g., Al-Shabbi, 1989; Baghdadi, 1985; Niblock, 2006), the English language has played a significant role for Saudi individuals and society alike. Al-Saraj (2014) observed that foreign language instruction is particularly important in Saudi Arabia because of rapidly increasing pressure for Saudi Arabian students to learn English. She added that globalization has created an intense demand for English language skills in the Saudi marketplace and that the Saudi educational system has changed to meet this demand. Faruk (2013) elaborated that the Saudi people have taken for granted the usefulness of English for advancing their careers, strengthening their nation, and spreading their religion. Thus, the significance of English in Saudi Arabia is not limited to its linguistic and communicative practicality; English is also fundamental to the social, economic, political, and religious domains at national and international levels.

Regarding economics, Mahboob \& Elyas (2014) emphasized that English has been particularly important in the Saudi education system because of its perceived economic value; the language has become intrinsically linked with the discourse of petroleum. For this reason, English is taught as a core subject in public and private Saudi schools and is the medium for training in major organizations and companies throughout the country, including 
Saudi Airlines, Saudi Aramco, and the Saudi Telecommunication Company. Alrashidi \& Phan (2015) stated that English has enabled Saudis to communicate with approximately 9.5 million foreign expatriates working in Saudi Arabia and that English language skills are among the competencies that Saudi workers must have to participate in the labor market and ultimately replace foreign expatriates. Furthermore, English plays a key role in enhancing foreign investments in Saudi Arabia.

The Saudi government has recognized education as the cornerstone of a knowledge-based economy that can support sustainable development and economic growth (Bashehab \& Buddhapriya, 2013) and provide an alternative to dependence on oil resources, which will one day run out. Therefore, the government invests heavily in education and provides incentives for Saudi citizens to continue learning. This attitude is evident in a scholarship program established by the late King Abdulah in 2005, which enables Saudi students to pursue tertiary studies in English-speaking countries such as the USA, UK, Australia, and Canada. As a result, there has been a tremendous increase in the number of Saudis studying overseas. For example, the number of Saudi students enrolling in American colleges and universities has increased dramatically, from fewer than 5000 prior to 2005 to more than 100,000 in 2013-2014 (Taylor \& Albasri, 2014). Sponsored students spend a couple of years studying abroad: undergraduate students receive four years of funding, Master's students receive two years of coverage and $\mathrm{PhD}$ students are funded for three years; with extensions granted in certain cases if the student did not graduate within the prescribed time. When those students return to Saudi Arabia, they are expected to contribute to an enormous expansion of EFL teaching and learning in the country. In addition to sending massive numbers of Saudi students abroad to obtain a Western education, the flourishing economy has enabled the government to recruit qualified teachers from around the globe to teach English in Saudi academic institutions.

Politically, learning English has enabled Saudis to communicate with the world and has allowed the country to become a key player in both regional and global foreign policy.

Socially, the use of English in Saudi Arabia enhances the rapid spread of technology and contributes to an increasingly borderless society. According to Alrashidi \& Phan (2015), access to such technology allows Saudis to communicate with people across geographical borders without barriers through social media.

In terms of religion, Islam in no way underestimates the value of learning foreign languages (including English); rather, it encourages doing so for a variety of practical reasons. One such reason is that English is the key means to communicate with approximately 11 million pilgrims who visit Saudi Arabia every year. Additionally, Rahman \& Alhaisoni (2013) and Osailan (2009) considered learning English a religious imperative for Saudi Arabian people because of its importance in teaching Islamic values and presenting the ideals of Islam to non-Arabic speakers, and thus contributing to the spread of Islam and helping to eliminate the misconceptions about Islam in the West.

\section{Factors behind the Low EFL Achievement Levels of Saudi EFL Learners}

The low English language competence of Saudi learners is a multidimensional and complex phenomenon. To address the major problems and to seek practical solutions, it is important to first address the factors underlying this problem. Low English language achievement can be attributed to a variety of interrelated factors ranging from learner-related variables (e.g., gender, motivation, and anxiety) to sociocultural variables (e.g., the influence of L1, society, culture, and religion). In addition, the variables of EFL instruction (i.e., teacher behavior and practices, the curriculum, and the teaching method) and other factors related to problems with the educational system in Saudi Arabia (e.g., overcrowded classes, a lack of teacher training, and a lack of technology) may also contribute to the poor EFL results.

Recent research on learner individual variables (see e.g., Lightbown \& Spada, 2013) shows that low achievement in the foreign language learning is the result of a complex interaction of both internal and external factors. For example, a controlling, aggressive teacher is an external factor that negatively affects learners' motivations, while the anxiety that such teachers instill in their students is an internal factor that negatively affects students' learning outcomes. Brophy (2004) highlighted this fact, stating that learners come to school with motivation and enthusiasm, but when they begin to encounter certain external practices, such as responding to their teachers' questions, completing their assignments, taking tests, and having their performances monitored, graded, and reported to their parents, learners may begin to find school anxiety-provoking and psychologically threatening.

\section{Discussion}

It is possible to classify the factors that affect the EFL achievement of Saudi learners into two main categories: internal/individual factors (the learner's demographic characteristics) and external factors (sociocultural variables, instructional variables, and problems with the educational system). 


\subsection{External Factors Affecting Saudi Learners' EFL Achievement}

The low EFL achievements of Saudi learners can be primarily attributed to factors that are outside of the learner's control. These external factors range from sociocultural variables, such as the impact of religious, social, and cultural beliefs, to factors related to the nature of EFL instruction and to faults in the EFL educational system in Saudi Arabia.

\subsubsection{Sociocultural Factors}

Sociocultural factors are the larger-scale forces within cultures and societies that affect the thoughts, feelings, and behaviors of individuals. They include the mother language as well as social, cultural and religious beliefs.

\subsubsection{The Use of the Arabic Mother Tongue (L1) as a Medium of Instruction}

Using the L1 in language classrooms has been widely criticized because it encourages students to think in the L1 and then translate their thoughts into the L2 (see e.g., Richard \& Rodgers, 2001; Shaikh, 1993), a practice that produces deficiencies in many aspects of learning EFL. Nonetheless, this is exactly the situation in Saudi EFL classrooms; the Arabic L1 is used extensively while teaching English as an L2 (e.g., Alkhatnai, 2011; Alhawsawi, 2013; Almutairi, 2008; Alnofaie, 2010; Alshammari, 2011; and Fareh, 2010). Past reserach attempted to define the portion of Arabic L1 use in English language classes in Saudi Arabia. Al-Abdan (1993) recruited 451 Saudi male and female teachers to explore their actual use of Arabic in teaching English. It was found that $75 \%$ of the teachers actually used Arabic for $10 \%$ of the class time and that $54.5 \%$ of them preferred to use Arabic for grammar while the majority (87.6\%) resorted to Arabic when explaining abstract words. More recently, Alshammari (2011) investigated the views of 13 Saudi teachers and 95 students towards the use of native Arabic in EFL classes. The study revealed that the majority of students (61\%) and teachers (69\%) believe that Arabic should be used in the English classroom for various purposes, such as explaining grammatical rules, introducing new vocabulary and giving exam instructions. According to Alshammari, those teachers claim that the use of Arabic is necessary to reduce time and increase students' comprehension and that the use of Arabic made the learning process more effective. In fact, the real reasons behind using the mother tongue in EFL classes in Saudi Arabia appear to be the teachers' lack of competence and confidence in using English and/or their desire to make their job easier (see Alhawsawi, 2013; Rabab'ah, 2005).

The teachers' reliance on this incorrect pedagogical practice is a major problem that hinders Saudi students' competence in English and has negative consequences. First, using the Arabic mother tongue as the language of instruction minimizes students' exposure to English, giving them very little or no opportunity to practice and communicate in the target language and thus undermining their communicative competence. Alharbi (2015) stated that the preference for using Arabic in Saudi EFL classrooms has resulted in the infrequent use of English in these classes. As a result, Saudi students usually lack the motivation to practice speaking English in the classroom with their teachers and classmates despite being in an EFL context, where classroom practice is crucial given the lack of opportunities to speak English outside the classroom.

The dominance of Arabic as an official language of the country and the primary medium of communication among Saudis has correspondingly undermined the value of English among Saudi students (Al-Mashary, 2006; Alqahtani, 2011; Khan, 2011). Alqahtani (2011) claimed that this view has resulted in students' assumption that English is worthless in both their academic and social lives, an attitude that contributes to their poor performance in English. Alharbi (2015) assumed that in this context, Saudi students may not understand why they should bother to achieve English language proficiency or why they really need to learn English when they can use their native Arabic to obtain what they need. Moreover, Zaid (1993) asserts that most Saudi students have some misconceptions about the significance of learning English; specifically, Saudi students generally believe that there is no need to learn English because of their misconception that after they finish their schooling, they will attend universities or obtain jobs where English is not required. Those students treat English as a subject that must be studied just to obtain the required exam score rather than as a tool for communication in their daily lives.

Lack of exposure to English is primarily due to the dominance of Arabic (the mother tongue) in the Saudi context. There are available possibilities for out-of-school exposure in Saudi Arabia such as the access to English websites via the Internet which is available nowadays in almost every middle-class home. Students have the opportunity to use English on sites like Facebook, Twitter, blogs, YouTube, etc.; they can access films in English, can watch TV programs/series in English, and can read English books and magazine online. In spite of the availability of those alternatives, Saudi students do not take benefit of them but rather browse the Internet and communicate in their daily life using their Arabic mother language. Khan (2011) reported that English in Saudi Arabia is treated as merely an academic subject because most Saudis communicate in their native language, Arabic, with their family, peers, friends and classmates and have few opportunities, if any, to speak English 
during daily interactions. He added that the lack of exposure to English in daily life activities hinders or even prevents Saudi students' from achieving a high level of English fluency and competence. Alharbi (2015) concurred with Khan's conclusions, confirming that the lack of realistic situations for practicing English communication skills outside the classroom is an obstacle that impedes the achievement of desired language outcomes in EFL countries because it limits students' opportunities to speak English.

\subsubsection{The Influence of the Society and Culture}

Ethnically, the majority of Saudi citizens (90\%) are Arabs, while a small minority (approximately $10 \%$ ) are of Asian and African origins (Alhawsawi, 2013). The surrounding society can either promote or discourage the effective learning of foreign languages. Alrahaili (2013) explained that Saudi society is a collective tribal society in the sense that conservative tribal traditions, tribal alliances and family ties are socially emphasized among the Saudi people, adding that Islamic identity is deeply rooted in Saudi society. Al-Saraj (2014) explained that Saudi Arabian culture tends to be conservative and religious and to have strong traditions, making Saudi culture resistant to changing or adopting new ways of life despite the increasing need for Saudi individuals to learn English.

As a result of these societal and cultural restrictions, some individuals in Saudi Arabia hold the misconception that learning English may affect the learning of Arabic, especially at younger ages, or might undermine local Saudi culture, customs, and identity (Al Dameg, 2011; Al-Seghayer, 2014; Elyas \& Picard, 2010; Mahboob \& Elyas, 2014). They emphasize that Arabic is essential for ensuring that Saudi Arabian identity, culture, and society are preserved. Despite the benefits of early language instruction, Saudi public elementary schools do not introduce English until the fourth grade (at the age of nine) — not in the first grade (at the age of six) — because of concerns that English language instruction will affect the Islamic or Arabic identity of young students (Elyas, 2008). Al-Seghayer (2014) emphasized that the fear that English will impact Arabic use and may erode Arabic culture, customs, and identity demotivates some Saudi students' attempts to learn English and in turn affects their academic achievement.

\subsubsection{The Role of Religion}

The official religion in Saudi Arabia is Islam, and the citizens of Saudi Arabia are predominantly Muslims. Moreover, the country is the birthplace of Islam, which means that the Islamic religion is at the heart of all aspects of Saudis' lives and dominates their culture, beliefs and customs, as well as governmental rules and policies. The rules and regulations that govern the educational system in Saudi Arabia are legalized in light of Islam. One Islamic regulation is that women must study and work in places completely separated from men. For this reason, there are no coeducational institutions, marking Saudi Arabia as one of the few countries with a single-sex school system (Al-Zarah, 2008). Wiseman (2010) attributed single-sex schooling in Saudi Arabia to the Islamic beliefs that remain at the core of the educational system and to other cultural, social and traditional values.

There is, however, no evidence that single-sex education negatively affects EFL learning in Saudi Arabia and it can be established then that the religion factor is playing a neutral role in this respect. Al-Johani (2009) clarified that although education in Saudi Arabia is separated based on gender, both sexes receive the same quality of education and educational facilities. For example, the stages of schooling are the same for both genders (e.g., primary, intermediate and secondary school), and curricula are almost identical, with small differences to meet different gender needs (Alrashidi \& Phan, 2015).

\subsubsection{Instructional Factors}

As used in this paper, instructional variables refer to three components of EFL instruction: the teacher, the curriculum, and the teaching method.

\subsubsection{The Influence of the Teacher}

Teachers play a significant role in students' learning of a foreign language because they can either facilitate or impede the learning process. In English language classes in Saudi Arabia, teachers are considered authoritative characters who dominate the learning process; they adopt the role of presenters of knowledge rather facilitators of learning (Alrabai, 2014b). Consequently, learners in this context rely on their teachers as the main source of knowledge (Alkubaidi, 2014) and are typically considered passive observers. Fareh (2010) indicated that English teachers in the Saudi context spend the majority of the lesson talking and rarely allow students a chance to speak or ask questions; as a result, students take a passive role in the learning process. Alharbi (2015) confirmed this finding, stating that teachers in English classes in Saudi Arabia play a central role because they control everything that happens in the classroom. In contrast, students are considered merely listeners and receivers of 
knowledge. This teacher-centered (as opposed to student-centered) learning environment tends to prevent students from developing satisfactory language competence (Ahmad, 2014; Alkubaidi, 2014; Alrabai, 2014a; Alrashidi \& Phan, 2015; Fareh, 2010; Rajab, 2013).

\subsubsection{The Influence of the Curriculum}

In Saudi government schools, the Ministry of Education provides a ready-made English curriculum that takes the beliefs, customs, values and traditions of Saudi Arabian society into account. English language textbooks are commonly referred to as English for Saudi Arabia, and the teaching/learning package includes three materials: a textbook and a workbook for the students and a teaching manual, which is referred to as the "teacher's book" (Al-Otaibi, 2004). The textbooks are identical at each grade level throughout the country, and they integrate all of the language skills (i.e., reading, writing, listening and speaking) with functional grammar and vocabulary. Even at the tertiary level, the teaching curriculum is not usually based on learners' goals, needs, and desires; rather, it is prescribed by university policymakers.

Curriculum design is considered a major challenge in the Saudi EFL education. Students in this context are often required to undergo instruction with a prescribed curriculum and must sometimes participate in preselected activities that they cannot choose on their own. Al-Subahi (1991) maintains that EFL curriculum designers in Saudi Arabia usually design curricula based on their personal perceptions rather than on students' actual needs, goals, and real-life concerns. Dörnyei (2001) states that one of the most demotivating factors for learners is a requirement to learn content that they see as having no relevance to their lives. Zaid (1993) presented a comprehensive analysis of the Saudi curriculum and identified another problem with the EFL curriculum in Saudi Arabia; namely, that a main reason behind the English language weakness among Saudi students is that the curriculum focuses on the content of the language itself, not on the use of the language as a communication vehicle.

Liton (2013) and Al-Saadat \& Al-Braik (2004) explain that although many curriculum reforms have been put into effect over the years in Saudi Arabia — some at a huge monetary cost—each has been poorly designed, badly implemented, and/or ineffectively evaluated during implementation. According to Al-Saadat \& Al-Braik (2004), considerable attention and resources have been directed toward planning reforms and designing EFL courses, but not enough time or attention has been spent on the actual implementation of the curriculum. Flying High is the newest EFL curriculum series (Brewster, Davies, \& Rogers, 2014) for Saudi elementary, middle, and high schools. The series objectives state that the series aims to improve English teaching by emphasizing intellectual, creative, and communicative skills; learner-centered approaches; and critical thinking skills. However, these objectives seem unrealistically ambitious. Using a 50-item survey, Almalki (2014) explored the perceptions of 42 Saudi EFL teachers concerning the quality of the newly introduced EFL curriculum. The study revealed that although teachers believed that the curriculum was high quality in terms of layout and instructional design, they encountered some difficulties implementing the new methodologies and strategies of the revised curriculum. The findings further indicated that teachers had only a minimal role in planning the curriculum and that neither teachers nor students were ready for the implementation of reforms. Moreover, the participating teachers reported that they were inadequately trained on how to utilize the new EFL curriculum.

\subsubsection{The Influence of the Teaching Method}

Most EFL learners in the Saudi context are taught using the traditional grammar-translation teaching method. Elyas \& Picard (2010) explain that the Saudi EFL context is a typical example of the traditional grammar-translation method of teaching, which is based on learning grammatical rules and then applying them by translating sentences from L2 to L1. Ahmad (2014) and Al-Seghayer (2014) also emphasize that Saudi teachers follow traditional methods of language teaching such as the audio-lingual and grammar-translation methods. According to them, these methodological choices mean that teachers use explicit instruction and teach discrete skills, emphasizing the memorization of grammatical rules and overlooking oral fluency. These teaching methods are therefore considered a barrier to developing speaking skills because they focus primarily on grammatical accuracy in written language rather than on the spoken form of the language.

Other flawed teaching practices are frequently employed in Saudi EFL classes. Al-Saraj (2014) notes that the Saudi high school system primarily utilizes rote methods of instruction and does not expect independent learning from students. Al-Misnad (1985) describes the traditional teaching philosophy in Saudi Arabia as one in which teachers are given lesson plans and material that they must simply present in the classrooms and that students are required to memorize information but not to think deeply about it. According to him, teachers walk their students through the textbooks page by page, and this approach continues in the higher education context. Thus, students are typically unaccustomed to being asked to pursue knowledge on their own; they expect their instructors to 
simply tell them what they need to know, which they then memorize and regurgitate on exams.

Because of these inappropriate teaching methods, EFL students develop inappropriate learning mechanisms, such as memorization and rote learning (Alkubaidi, 2014; Almutairi, 2008; Alrabai, 2014a; Fareh, 2010; Rajab, 2013; etc.). According to Alrashidi \& Phan (2015), most students in Saudi EFL classes employ memorization as their sole strategy for learning; they memorize things such as paragraphs, grammar rules or vocabulary without understanding their meanings or the way in which they are formed. Relying on memorization is an ineffective learning strategy that makes it impossible for Saudi EFL learners to even come close to developing the required competence in the target language because they can pass exams and attain high marks without actually mastering language skills.

\subsubsection{Faults of the Educational System}

In spite of the huge annual monetary budget the Saudi government exert to improve education in the country, there are some faults in the Saudi educational system such as untrained teachers, overcrowded classrooms, lack of proper teaching/learning facilities, lack of access to technology, etc. The presentence of such problems is a clear indicator that the enormous efforts paid by the government are not properly utilized but rather misused.

One fault of the Saudi educational system lies in its exams and the mechanism for promotion. Students are not usually tested or promoted based on their actual competence in the foreign language. For example, teachers provide summaries for each unit of the curriculum and ask students to study these summaries for the exam. To pass the exam, students are primarily required to memorize information from the textbook and duplicate it in their exam papers (Syed, 2003). These practices are a major challenge that impedes students' creativity and imagination while learning as they offer no opportunity for learners to aim beyond a high exam mark but, instead, allow low-proficiency students to achieve excellent grades. Moreover, the mechanism for promotion makes English a low-priority subject since students can progress to the next grade even if they did not achieve the required competence in the language. Nonetheless, Rabab'ah (2002) reported that in some cases, graduates of Saudi institutions are not recommended for employment because of their inappropriate level of English language proficiency. Some evidence for this is based on the author's personal experience: male graduates of the Department of English at King Khalid University (Mahayel Aseer Campus) usually graduate with high GPAs (Note 1) after at least four years of study at the department, but they usually do not pass the job placement test required to join the EFL teaching profession. Despite their artificially high GPAs, these graduates often remain unemployed (some for a couple of years) because of the very low language competence they achieve during their study. This phenomenon can be ascribed to institutional faults that allow students to attain high passing marks without acquiring the necessary language competence.

Another fault of the Saudi education system is that teachers are not required to have teaching certification to join the teaching profession; they only need an undergraduate degree. The lack of certification in foreign language instruction might indicate that teachers have not received adequate training on the use of the extensive and diverse instruction techniques that require active participation and independent inquiry from students. If such techniques are not carried over into the EFL classrooms, students will not be expected to ask and answer questions in class, give in-class presentations, or work together in groups. Al-Saraj (2014) reported that most Saudi students have never been required to engage in these tasks, a finding that may be attributable to teachers' lack of training in using these techniques.

A third fault of the educational system is that EFL classes in Saudi Arabia are typically overcrowded. Overcrowded classes have been found to be a barrier that limits contact between teachers and students, minimizes students' exposure to the language and negatively impacts learning outcomes (see Al-Mohanna, 2010; Bahanshal, 2013). Bahanshal (2013) clarified that classes in Saudi government schools vary in size. While the average number of students is between 30 and 45 in Dammam in the east or Jeddah in the west of Saudi Arabia, for example, this number easily rises above 50 in most schools in southern Saudi Arabia. This variance is related to the number of private schools available in major cities such as Riyadh, Jeddah, and Dammam, home to most of the upper class families in the country who can afford the costs of private schools. Bahanshal (2013) interviewed six Saudi secondary school English teachers with considerable experience (more than 15 years) teaching English to large classes to gain some understanding of their attitudes and beliefs toward teaching a large class. All of the participants in this study believed that teaching large classes is a huge burden because it is exhausting. The teachers also stated that teaching large classes hinders the effectiveness of both the learning and teaching processes in a variety of ways. One of the greatest problems in this respect is classroom management, which is time consuming, especially when misbehaving students force the teacher to focus on behavior issues rather than on more productive actions. Additionally, teachers usually have little, if any, opportunity to assess 
and evaluate their students' performances, discuss their problems, correct their mistakes, or provide any useful and constructive feedback. Diversity among students is another factor that confuses teachers and increases the pressures they experience, leaving them mentally and physically exhausted. Students in large classes are usually less motivated, less satisfied, and uninterested in either the lesson or the activities the teacher is presenting because of the limited or absent support and attention they receive from teachers compared with their peers in smaller classes. The limited space in overcrowded classes is another barrier that prevents teachers from moving around freely to monitor, observe and assess students during activities. Finally, students in large classes usually have fewer chances to participate effectively and use the target language.

A fourth systemic problem is the lack of technology in EFL classes. Almutairi (2008) explained that despite the crucial benefits of technology, most Saudi schools lack English learning facilities such as language labs, educational films or tape recorders. He added that when such resources are available, they are usually out of order because of poor maintenance and a lack of training in their correct use. Moreover, Alharbi (2015) stated that the Saudi educational system has underestimated the benefits of using technology in language learning. She added that computers, recorders and projectors are alien words in Saudi schools. Morris (2011) explored the ways that technology-specifically, the use of laptop computers and cellular phones-can be incorporated in the EFL classroom to enhance learning and lower the affective filter of male Saudi Arabian university students. He found that creating ways to allow students to use their laptops and cellular phones constructively can help lower these students' affective filters and aid their learning. Participants in the Alkhatnai (2011) study noted that some online learning activities cannot be replicated in a traditional classroom setting and that they were able to overcome some of the problems associated with face-to-face classroom dynamics when working online. They mentioned that they did not experience problems with speaking up, speaking out, asking questions, engaging with peers, or monitoring and reflecting on learning when interacting online.

\subsection{Internal Factors Affecting Saudi Learners' EFL Achievement}

\subsubsection{Demographic Variables}

Demographic variables are those factors that pertain to the learner himself/herself, such as gender, age, motivation, attitudes, aptitude, anxiety, autonomy, learning strategies, etc.

\subsubsection{Role of Gender}

In a study sample of 315 Saudi university students (177 males and 138 females), Ismail (2015) reported that females significantly outperformed males in English achievement. Likewise, Al-Nujaidi (2003) reported that significant gender differences favoring females were found in Saudi EFL learners' performances on tests. Salem (2006), however, found no statistically significant differences between males and females regarding EFL achievement. Regardless of Salem's study findings, it appears that the gender variable plays a role in EFL achievement among Saudi learners in that females outperform males in general; which is a pattern present in other cultures and societies as well.

\subsubsection{Role of Attitudes}

Despite the negative view that the majority of Saudis have held about English in the past, there has been a noticeable recent shift in Saudi learners' attitudes towards English in the very recent years. Faruk (2014) stated that Saudis' attitudes toward English are becoming highly positive because most Saudi people believe that English is vital to the country's future prosperity and that English is significantly needed in various domains. Statistical analyses of the data gathered by Alrahaili (2013) from 510 male and female university students in Saudi Arabia revealed that these Saudi EFL learners hold generally positive attitudes toward English and its speakers and towards their learning situations but are also generally opposed to accepting the target language group's social and religious values. Another finding of this study was that Saudi learners' attitudes were related to both intended and actual learning efforts (i.e., motivational intensity), although the intended efforts were not necessarily reflected in the actual efforts of many of the research participants. Alrahaili (2013) concluded that his research findings demonstrated that the target language group remains a salient issue for Saudi EFL learners. Other studies found that the positive shift in attitude has recently extended to include the target language's culture. Using an open-ended questionnaire, Hagler (2014) explored the attitudes of 210 male and female Saudi university students toward Western culture. A clear majority of these students showed a positive disposition toward Western culture and indicated that they liked some aspects of the Western culture. The study concluded that these Saudi students are predisposed to interact favorably with the West.

The recent change in social attitudes and perceptions of Saudis towards English could be attributed to the growing access they have to the target language and its community and culture via the social network websites 
and media. In addition, the launch of King Abdulah Scholarship Program in 2005 was associated with a rising interest among Saudi students to take university courses in English-speaking universities and therefore playing a major role in the turning positive shift in Saudi students' attitudes towards English language and its community. It is highly anticipated that this shift in the attitudes will contribute in eliminating the negative attitudes and faulty beliefs that Saudi EFL learners usually associate with learning English and will also contribute in altering the perceptions of Saudis about the value of English language.

Saudi students' attitudes toward learning English have been found to determine their levels of competence in the language. In a study investigating the relationship between Saudi EFL students' attitudes towards learning English and their academic achievement, Alsamadani \& Ibnian (2015) found that students with high GPAs had the highest positive attitudes towards learning English, followed by the medium-GPA students and finally the low-GPA students.

\subsubsection{Role of Aptitude}

Moskovsky, Alshahrani, Ratcheva, \& Paolini (2015) claimed that no single study has investigated the impact of foreign language aptitude on English proficiency in the Saudi context. They attributed the lack of interest in foreign language aptitude research among Saudi applied linguists to the lack of a valid, reliable Arabic version of the foreign language aptitude test. For this reason, Moskovsky et al. (2015) executed a study that aimed to develop a foreign language aptitude test for Arabic native speakers and to determine whether there was a relationship between foreign language aptitude and second language proficiency among 56 Saudi male university students. The researchers examined how well the participants' scores on the Modern Language Aptitude Test (MLAT) predicted their success in a foreign language proficiency test (TOEFL) pre and post a seven-month English course. They found that in the study population, foreign language aptitude manifested as a stable trait and thus plays a neutral role in English language achievement among Saudi learners.

\subsubsection{Role of Language Learning Strategies (LLSs) and Learning Styles}

Utilizing the most inclusive taxonomy of language learning strategies, Oxford's (1990), Alhaisoni (2012) investigated the type and frequency of LLSs among a population of 701 male and female Saudi EFL students. The results revealed that the Saudi students employed LLSs at low to medium frequency. They further showed that cognitive strategies (e.g., practicing, receiving and sending messages, analyzing and reasoning, and creating structure for input and output); and metacognitive strategies (e.g., organizing, setting goals, planning language tasks, looking for practice opportunities, self-monitoring and self-evaluating) were the most frequent strategies utilized by the study population. Affective strategies such as controlling anxiety, encouraging oneself, and taking emotional temperature; and memory strategies like asking questions, cooperating, and empathizing with others were the least frequent strategies utilized by learners. These findings were in line with those of Al-Otaibi (2004), who found that Saudi students reported using LLSs on average and that those students used memory strategies infrequently. In addition to these two studies, Al-Qahtani's (2013) study showed that students utilize all types of LLSs, with cognitive strategies being the most frequently used. This study also explored possible associations between English language proficiency grade/achievement and LLSs and found that achievement in English was positively and significantly associated with social learning strategies.

Alqahtani (2011) conducted a study to identify the preferred learning styles of Saudi EFL learners and found that Saudi EFL learners prefer tactile, auditory, visual, group, kinesthetic and individual learning styles, in that order. Another finding of this study was that students' perceptions of their learning styles are affected by their personality types, cultural beliefs, and their teacher's teaching style.

\subsubsection{Role of Motivation}

A significant characteristic of Saudi EFL learners that negatively affects their competence is a lack of motivation for learning English (see, e.g., Al-Khairy, 2013a, Alrabai, 2014b; Khan, 2011). Fareh (2010) confirmed this attitude toward English learning in the Saudi EFL context, reporting that most students are unmotivated and do not want to learn. Al-Johani (2009) and Khan (2011) also asserted that EFL learners in Saudi Arabia lack motivation, which interferes with their progress in developing English proficiency.

Based on the findings of experimental investigations, Alrabai $(2011,2014 b$, and 2014c) concluded that the reasons for Saudis' low motivation to learn English are diverse and complex; however, the prime reasons could be inappropriate teacher behaviors, students' low self-esteem and self-confidence, high language anxiety, low motivational intensity, low autonomy, and inappropriate methods for teaching EFL. In another empirical study, Al-Khairy (2013a) reported that Saudi university undergraduates felt demotivated because of factors that include unappealing textbooks, improper English faculty behaviors, peer pressure, inappropriate teaching methods, 
insufficient use of modern teaching aids, and the difficulty of English vocabulary and grammar.

Among these demotivating factors, teachers are most responsible for students' lack of motivation. Al-Johani (2009) highlighted some types of EFL teacher misconduct that undermine students' foreign language motivation in Saudi Arabia. He stated that in most English classes, teachers demotivate students because they do not provide realistic situations when presenting lessons, do not encourage or praise students' participation and ideas, tend to overcorrect students' mistakes, and constantly criticize students' learning attempts (cited in Alrashidi \& Phan, 2015 , p. 39). Khan (2011) regarded the lack of teacher support for students in the classroom as another demotivating factor. He noted that EFL teachers in Saudi Arabia commonly do not follow up on their students' work to determine whether they have improved and that students are usually left alone without any guidance from the teacher. This lack of teacher input hinders students' motivation and, accordingly, their English competence. In addition, EFL teachers in Saudi Arabia fail to pay attention to important factors that are strongly associated with learner motivation. For example, Alrabai (2014b) concluded that promoting learners' autonomy is the most rarely used technique for enhancing learners' motivation in Saudi EFL classes. The sample of teachers in this study also indicated that they did not usually incorporate efforts to reduce language anxiety for the purpose of enhancing learners' motivation into their teaching practices.

\subsubsection{Role Language Anxiety}

Language anxiety manifests itself prominently among most Saudi EFL learners (Alrabai, 2015; Al-Saraj, 2014; Javid, 2014; Mohammed, 2015; among many others). Alrabai (2014a) emphasized that one significant reason behind the low English competence of Saudi learners could be the anxiety that is often prevalent in English language classes in Saudi Arabia. He stated that most learners in English language classes in this context often appear reluctant to participate in classroom discourse, are unwilling to provide responses, seldom ask questions, are unwilling to engage in class discussions and are overly dependent on their teacher. Both male and female learners in the Saudi EFL context exhibit the same degree of language anxiety, a fact emphasized by Alshahrani \& Alandal (2015), who showed that gender does not play a significant role in anxiety toward foreign language learning among Saudi students.

Past research conducted in the Saudi EFL context (including Alrabai, 2014a; 2015; Al-Saraj, 2014; Alshahrani \& Alandal, 2015; and Javid, 2014) identified fear of negative evaluation, communication apprehension, comprehension apprehension, and language tests as the major sources of language anxiety among Saudi EFL learners. This list of sources is not exhaustive, however, because there are many other factors at play. Al-Saraj (2014) indicated that EFL teacher characteristics and behaviors in the Saudi context are major factors that evoke student anxiety. Alrabai (2014a) highlighted some of these practices, such as the absence of teacher support, unsympathetic teachers, negative student performance evaluations, teachers' lack of time for personal attention, threatening questioning styles, intolerance of learner errors, harsh correction or overcorrection of students' mistakes, assessment procedures that depend primarily on written tests, and the students' sense of being judged by the teacher or wanting to impress the teacher.

Tanveer (2007) identified other factors that contributed to language anxiety in the Saudi EFL context, such as a threatening classroom atmosphere, a lack of learner involvement in class discussions and decision making, competitive learning conditions, overcrowded EFL classes, lack of learner involvement, the ready-made EFL curriculum that is often more concerned with the quantity than the quality of the content, and the strict classroom rules in schools in Saudi Arabia, which do not allow learners to experience sufficient freedom and therefore evoke feelings of anxiety. Moreover, Hamouda (2013) recognized the low perceived self-esteem that Saudi EFL learners usually exhibit, citing the shy and reluctant personalities of Saudi EFL learners attempting to communicate in a foreign language as additional contributors to their language anxieties.

The misconceptions that many Saudi Arabian learners hold regarding learning English as a foreign language also lead to significant language anxiety. Alrasheed (2012) noted some of these faulty beliefs; for example, that mastering a foreign language is an overwhelming task that requires special learning abilities and intelligence, that younger language learners are more successful than adults, that learning a foreign language is simply a matter of memorizing vocabulary words and grammatical rules, that a learner is supposed to be fluent or have a perfect accent in the foreign language, that learners should understand every word they read or hear in the language class and that when speaking in the foreign language, learners should be grammatically perfect.

\subsubsection{Role of Learner Autonomy}

Learner autonomy is regarded as irrelevant in formal foreign language education in countries like Saudi Arabia, which have a reputation for being anti-autonomy. Promoting readiness for spontaneous, self-directed, lifelong learning and enhancing such metacognitive skills as self-assessment, recognition of one's strengths and 
weaknesses, and planning and implementing suitable strategies - all of which are important features of learner autonomy - are not incorporated into EFL education in Saudi Arabia. Despite increasing worldwide interest in learner autonomy in language education over the past few decades, this crucial concept has gone unnoticed in the Saudi EFL context. To this researcher's best knowledge, no single study to date has investigated the issue of EFL learner autonomy in Saudi Arabia. The reasons behind the ignorance of learner autonomy in the Saudi EFL context are diverse and multidimensional. One significant reason is that EFL instruction in Saudi Arabia is often based on the misconception that there is a fixed world of knowledge that students must know. Teacher-centered approaches and "spoon-feeding" methods are extremely prevalent. As mentioned before, in this context, teachers are regarded as authorities, knowledge givers, error correctors, and learning controllers. Consequently, there is very little or no room for student-initiated learning, independent thinking or interaction among students in EFL classes in Saudi Arabia. As a result, learner-centered approaches and self-directed learning remain unrecognized in Saudi EFL contexts. Another reason for the ignorance regarding learner autonomy is that this concept has been left untouched by the decision-making facets of Saudi education. For instance, promoting learner autonomy is not an explicit goal for the EFL learning process in Saudi Arabia, and the foreign language curriculum is an area where learner autonomy is extremely overlooked. In Saudi Arabia, course design is controlled by a binding curriculum that defines the general outlines of each course, and the choices available to learners are very limited. Moreover, the absence of learner autonomy in Saudi EFL classes reflects teachers' lack of awareness of the importance of learner autonomy.

As a result, Saudi EFL students are rarely engaged in autonomous learning because it has not been part of their culture or their educational background. Instead, learners are driven by lectures, heavily dependent on textbooks, disoriented, anxious, demotivated, and lack the capacity to take charge of decision making in all areas of learning. Accordingly, students fail to identify and achieve their learning goals and are traditionally described as dependent, reticent, and passive.

\subsubsection{Problems with Mastering Language Skills}

As a result of the previously mentioned barriers, Saudi EFL learners encounter difficulties mastering various language skills. Because of space limitations, this paper will present and discuss only problems related to language production skills (speaking and writing).

\subsubsection{Problems in Speaking and Pronunciation}

Saudi EFL learners usually have problems developing the productive skill of speaking. These problems do not seem to arise from specific learner characteristics but from external factors over which Saudi learners have little or no control such as the lack of exposure to the foreign language-which itself results from the dominance of the Arabic L1. A significant reason for this difficulty communicating in the target language is the lack of sufficient opportunities to practice English in the classroom. Aljumah (2011) argued that Saudi students find it inappropriate to speak in class - and even when they do, they speak very little. He explained that in EFL/ESL classroom interactions in Saudi Arabia, teachers and students are usually on opposing sides: teachers speak constantly, whereas students mumble and swallow their words or say nothing (p. 85). Rabab'ah (2002) confirmed this, noting that both public school and university students in Saudi Arabia are taught the same way: with no English practice in the classroom.

Using questionnaire surveys and interviews, Al-ma'shy (2011) investigated the causes underlying the EFL speaking difficulties among 240 Saudi secondary school students. He confirmed that Saudi secondary school students are generally weak in speaking English, and he attributed this weakness to factors associated with the English textbooks used at the secondary level and with the English teachers. Alharbi (2015) focused on a significant cause for this phenomenon, maintaining that in addition to the students' poor knowledge of the grammar and vocabulary of the target language, EFL teachers in Saudi Arabia cover most of the important points in the students' first language.

Based on more than 15 years' experience teaching EFL in Saudi Arabia, Hamouda (2013) observed that Saudi EFL learners have serious deficiencies in speaking skills and usually appear reluctant to speak in English language class for a variety of reasons. In addition to the learners' low English proficiency and lack of vocabulary, Hamouda considered factors related to language anxiety (e.g., the fear of speaking in front of others, fear of negative teacher evaluations, shyness, lack of confidence and preparation, low self-esteem, fear of comparisons with other students, and fear of making mistakes and being laughed at) as contributors to problems communicating in the foreign language.

The problems that Saudi EFL learners encounter in communicating in English also lead to pronunciation problems. Thaher (2005) reported that Saudi EFL students are usually afraid of being laughed at or criticized by 
others because of inaccurate pronunciation. In another study, Hamouda (2013) found that $71.70 \%$ of Saudi learners are worried about their pronunciation when they speak in class and that $55.97 \%$ of subjects expressed embarrassment when they mispronounced words.

\subsubsection{Problems in Writing}

Javid \& Umer (2014) conducted a comprehensive investigation to identify the major areas of difficulty in academic writing, the factors that caused these difficulties, and possible corrective measures using a sample of 194 Saudi EFL learners. The study findings revealed that Saudi EFL learners have serious problems in their academic writing because of weaknesses with using appropriate lexical items and grammar; organizing ideas; spelling; and using prepositions, irregular verbs, articles, punctuation, suffixes and prefixes.

In another empirical investigation, Al-Khairy (2013b) found that Saudi undergraduates majoring in English have weak writing skills and commit numerous errors in their academic writing. Moreover, those learners are usually challenged to write only at the sentence level or, at the maximum, at the paragraph level. They also usually appear unable to write different types of essays. The study also revealed that even Saudi undergraduate English majors (who should have better skills than their counterparts from other departments) show multiple problems in their academic writing (e.g., lexical items, irregular verbs, prepositions, spelling, and punctuation). The study identified the following reasons for Saudi English-major undergraduates' writing problems: students' low English language proficiency, an insufficient number of language courses offered at the academic institution where the study was conducted, the teachers' lack of interest in assigning writing tasks, use of inappropriate teaching methods, insufficient opportunities to practice writing in the classroom, insufficient audiovisual facilities, and insufficient use of dictionaries.

\section{Conclusions and Implications}

This paper focuses primarily on a single significant trait of Saudi EFL learners- their low competence in English language - and investigates some of the subtraits and factors that contribute to this phenomenon. While certain factors, including government efforts, the growing economy, and the recent positive shift in students' attitudes towards English, suggest the possibility of a positive shift in EFL teaching and learning in Saudi Arabia, other demographic, sociocultural, instructional, and institutional factors presented in the course of this paper indicate the contrary. It is obvious that sociocultural, instructional, and institutional factors are negatively affecting the internal factors of Saudi EFL learners, resulting in inevitable psychological and academic problems for those students.

Improving Saudi learners' competence in EFL will require a systematic, extensive, and careful treatment of the underlying causes and contributing factors of this phenomenon. Such improvements would need to be launched from both outside and inside the classroom. The government and education policymakers must lay the cornerstone for necessary changes in Saudi EFL education outside the classroom and then move these changes into the classroom for implementation by teachers and learners. Some practical implications and recommendations to help the four partners in EFL education in Saudi Arabia (the government, education policymakers, teachers, and learners) put the proposed changes into practice are presented below.

Considerable efforts must be made to address the existing problems in the educational system. First, the Ministry of Education should introduce English as a compulsory course starting in the first grade in public elementary schools. This will allow students to reap the benefits of a younger age for second language acquisition. Second, the Saudi government should consider the long-term option of transforming some public schools into bilingual schools. Doing so would strongly promote learning/teaching English in the country because it would increase the learners' exposure to the foreign language.

Third, to offset the counterproductive influence of society, the government needs to launch programs that aim to expand the Saudi population's sense of the importance of learning English. These programs should acknowledge that English is the world's most widely spoken language and is the language of science, technology, politics, and world business. Such programs should also highlight the practical ways that learning English can benefit Saudi individuals and society, such as those elaborated in the first section of this paper.

The challenge of overcrowded classes in Saudi Arabia is an institutional problem of the first degree. The main cause of this problem is a shortage of classrooms and teaching staff. The simple solution is for the government to construct more institutions, hire more teaching staff, and provide sufficient learning facilities.

Teachers should receive comprehensive training both before they begin teaching and throughout their teaching careers. Those teachers should be well trained on how to utilize the most up-to-date teaching methodologies and modern technology (devices and applications) in EFL teaching. Any reforms in EFL curriculum designs must 
take the teachers' point of view into account and should be accompanied by sessions to train EFL teachers to implement the new curriculum. Teachers should also be trained on how to incorporate strategies for promoting learners' motivation, increasing their autonomy, and reducing their anxiety into their language teaching practices.

Regarding curriculum design and material preparation, the curriculum should be reformed and shaped by teachers' perceptions and should be based on learners' interests, needs, goals, experiences, daily life activities, and real-world situations. Some studies (e.g., Shawer, 2010) have found that when teachers are included in decision-making processes, such as curriculum design, they are more likely to enable the success of new changes in any educational system. Dörnyei (2001) recommends trying to make the content of the curriculum motivational by relating the subject content to students' everyday experiences and backgrounds. Curriculum designers and material developers should incorporate a variety of learning strategies associated with success in learning a second language. The curriculum should also be constructed in a way that takes advantage of different learning styles. This will make the curriculum goal-efficient. Curriculum designers should also emphasize the quality rather than the quantity of the curriculum content by reducing the density of the EFL curriculum and alternatively adding communicative exercises and activities such as group and pair work, games, puzzles and role play to the curriculum to help students practice communicative tasks in real-life situations. The designed tasks should be within the students' abilities to reduce their fear of failure and boost their confidence that they can successfully complete the tasks.

To address the problems EFL students have in speaking, the Ministry of Education should offer opportunities for spoken English at both school and tertiary levels. Effective English teaching aids, such as language laboratories, videos, and computers, should be provided and used. The number of English contact hours (periods) should be increased to give students sufficient opportunities to practice using English language and thus improve their speaking skills. While qualifications and teaching experience are the most distinctive features of an excellent ESL/EFL teacher, it is highly recommended that the government hire native English-speaking teachers to teach speaking skills. Native speakers are believed to be the best at teaching such skills because of their own language fluency and accuracy. This change would likely improve learners' communicative competence. Moreover, teachers should decrease their L1 use in the EFL classroom. Teachers and students should only communicate in English in the classroom so that students can improve their speaking skills through real practice. Contemporary techniques, such as pair work, group work, role playing and interviews, should be employed to encourage shy and reluctant students to participate and discuss their opinions with their classmates and teachers.

Regarding writing, Al Murshidi (2014) reported that Saudi students need more coursework in academic writing to prepare them for their future disciplines. Al-Khairy (2013b) recommended that faculty give students intensive practice in writing paragraphs of reasonable length. He strongly suggested that, considering the low competence of Saudi students who join university English departments, language courses should be increased to strengthen language skills in general and writing in particular.

Most of the implications and recommendations made in this paper will be presented to EFL teachers in Saudi Arabia because they are the essential players at the heart of the EFL education process. Teachers should, above all, pay careful attention to students' psychological and emotional characteristics by enhancing positive affective variables such as motivation and autonomy, while simultaneously making efforts to minimize negative feelings such as language anxiety.

Regarding learner motivation, teachers should demonstrate competence in English and be confident, pleasant, kind, fair, outgoing, cheerful, considerate, supportive of students, mindful of students' individual differences, and dynamic in their presentations. Teachers should show convincing faith in students' ability to succeed; and they should provide students with encouragement, positive feedback and appraisals of their performance.

To address learner anxiety, EFL teachers should behave as models and avoid antagonistic behavior toward students, such as aggressive criticism, overcorrecting errors or blaming students when they make mistakes, forcing students to compete, and publicly comparing the performance or grades of different students. Teachers should also tackle the beliefs and misconceptions that learners have that affect their learning success. There are many recent resources that EFL teachers in Saudi Arabia should consult because they provide practical methods for addressing learner anxiety (Alrabai, 2015; Alrabai, 2014a; Alrabai, 2014d; Hashemi \& Abbasi, 2013; Javid, 2014; Kondo \& Ling, 2004; Nagahashi, 2007; Tallon, 2008; Tsiplakides \& Keramida, 2009).

Because learner autonomy is all about learners' voices being heard, the need for learner autonomy as an aspect of education in Saudi Arabia is well justified. It is, therefore, important to reflect on teaching practices that take learner autonomy into account. Instead of controlling students, teachers should operate as learning facilitators by helping students develop self-awareness, giving them more control over their learning, and involving them in 
decision-making.

Instead of utilizing outdated teaching approaches that underestimate learner's communicative competence, teachers should adopt contemporary teaching methods based on students' needs, goals and learning preferred styles; furthermore, they should allow students to talk and actually use the language in both the classroom and in the real-life situations outside of class. The communicative language teaching (CLT) approach could be a good option in this regard. Students should also be involved in extracurricular activities that stimulate their imaginations and creativity to help them think beyond the content of the ready-made curriculum.

Regarding LLSs, it is recommended that Saudi EFL teachers should pay careful attention to diversifying their teaching styles to accommodate different learning styles and learning strategies.

Educators should take advantage of technology and invest in providing learners with the best learning opportunities. Students should have reliable access to technology, as limited access to technology can result in limited enthusiasm for online classes. Alharbi (2015) suggests that authenticity and technological devices are essential in creating a lively classroom and avoiding boring textbooks and tasks. Laptop computers, cellular phones, and YouTube EDU channels should be incorporated into the EFL classroom to enhance the quality and effectiveness of learning.

Regarding the management of large classes, teachers should have the skills to professionally manage the classroom and students' behavior. To do this, clear and strict norms must be established and stated upon the first meeting with students, and these rules should be applied effectively. Different methods and approaches must be adopted and utilized to facilitate the learning process in overcrowded classes. A student-centered rather than teacher-centered approach is highly recommended because it allows learners to become more responsible and involved in the learning process rather than being passive learners. Another helpful solution that might facilitate teaching and save time in large classes is the utilization of collaborative tasks that allow greater interaction among students and thus enable them to become active participants in learning activities, creating a more effective and productive learning environment. Group work, pair work, peer editing, games, role plays and interviews are some of these tasks that should be used in large classes because they promote cognitive elaboration, enhance critical thinking, provide feedback, promote social and emotional development, foster an appreciation of diversity and reduce student attrition.

To increase learners' exposure to the language, classroom interactions between the teacher and students should be conducted in the target language. The teacher use of the Arabic first language is to be restricted to the lowest possible levels and only when the use of English becomes unpractical. Learners should also be encouraged to practice English outside the classroom by using social media and watching English-language media, such as television programming. Students should have access to an English library as well as online sources such as electronic English newspapers, articles, journals, magazines, and stories, and they should be able to use information from these sources in classroom activities.

A significant limitation of this study is that it did not provide details regarding the role of age in the EFL achievements of Saudi learners. This omission is solely related to the paucity of research on this variable in the Saudi EFL context, which could be attributable to the fact that English language instruction was not introduced to young learners in Saudi Arabia until very recently-within the past decade. It is also quite challenging to recruit young participants in Saudi Arabia because of social, ethical, and institutional considerations. The role of other variables such as learners' personalities and cognitive abilities have not been discussed either-also due to the very limited research available on these variables in the Saudi EFL context. It therefore falls on future research to investigate and evaluate the role of these variables in EFL education in Saudi Arabia.

\section{References}

Abdan, A. A. (1993). A filed Study of the Use of Arabic in EFL Classrooms in the Saudi Intermediate Public Schools. Journal of King Saud University, 5(2), 396-426.

Ahmad, A. M. (2014). Kumaravadivelu's framework as a basis for improving English language teaching in Saudi Arabia: Opportunities and challenges. English Language Teaching, 7, 96-110.

Al Dameg, K. A. (2011). The suitable age for learning foreign languages in public education. Damascus University Journal, 27, 753-811.

Al Murshidi, G. (2014). Emirati and Saudi students' writing challenges at U.S. Universities. English Language Teaching, 7, 87-95. http://dx.doi.org/10.5539/elt.v7n6p87

Alhaisoni, E. (2012). Language Learning Strategy Use of Saudi EFL Students in an Intensive English Learning 
Context. Asian Social Science, 8(13), 115-127. http://dx.doi.org/10.5539/ass.v8n13p115

Alharbi, H. (2015). Improving Students' English Speaking Proficiency in Saudi Public Schools. International Journal of Instruction, 8(1), 105-116. http://dx.doi.org/10.12973/iji.2015.818a

Alhawsawi, S. (2013). Investigating student experiences of learning English as a foreign language in a preparatory programme in a Saudi university. Doctoral Dissertation. University of Sussex, Brighton, UK.

Al-Johani, H. M. (2009). Finding a way forward the impact of teachers strategies, beliefs and knowledge on teaching English as a foreign language in Saudi Arabia. Doctoral Dissertation. University of Strathclyde, Glasgow, Scotland, UK.

Aljumah, F. (2011). Developing Saudi EFL Students' Oral Skills: An Integrative Approach. English Language Teaching, 4(3), 84-89. http://dx.doi.org/10.5539/elt.v4n3p84

Al-Khairy, M. (2013a). English as a foreign language learning demotivational factors as perceived by Saudi undergraduates. European Scientific Journal, 9, 365-382.

Al-Khairy, M. A. (2013b). Saudi English-Major Undergraduates' Academic Writing Problems: A Taif University Perspective. English Language Teaching, 6(6), 1-12. http://dx.doi.org/10.5539/elt.v6n6p1

Alkhatnai, M. (2011). Learning styles of EFL Saudi college-level students in online and traditional educational environments. PhD Thesis. Indiana University of Pennsylvania, Indiana, PA.

Alkubaidi, M. A. (2014). The relationship between Saudi English major university students' writing performance and their learning style and strategy use. English Language Teaching, 7(4), 83-95. http://dx.doi.org/10.5539/elt.v7n4p83

Al-ma'shy, A. A . (2011). Causes of EFL speaking weakness in Saudi secondary schools in Al-Gunfuthah City. Unpublished Master's thesis. King Saud University, Riyadh, Kingdom of Saudi Arabia.

Almalki, M. M. (2014). Teacher perceptions of new English as a foreign language (EFL) curriculum in Saudi Arabia. Master's Thesis. State University of New York at Fredonia, Fredonia, NY.

Al-Mashary, A. (2006). The problems of teaching English to the secondary schools students in KSA from teachers and supervisors perspectives. Master's Thesis. King Saud University: Riyadh, Kingdom of Saudi Arabia.

Al-Misnad, S. (1985). The development of modern education in the Gulf. London, UK: Ithaca Press.

Al-Mohanna, A. (2010). English language teaching in Saudi Arabian context: How communicatively oriented is it? Journal of King Saud University: Languages and Translation, 22(1), 69-88.

Almutairi, N. H. (2008). The influence of educational and sociocultural factors on the learning styles and strategies of female students in Saudi Arabia. Doctoral Dissertation. University of Leicester, Leicester, UK.

Alnofaie, H. (2010). The attitude of teachers and students towards using Arabic in EFL classrooms in Saudi public schools-A case study. Novitas-Royal, 4(1), 64-95.

Al-Nujaidi, A. (2003). The relationship between vocabaulry size, reading strategies, and reading comprehension of EFL learners in Saudi Arabia. PhD Dissertation. Oklahoma State University, Stillwater, OK.

Al-Otaibi, G. N. (2004). Language learning strategy use among Saudi EFL students and its relationship to language proficiency level, gender and motivation. $\mathrm{PhD}$ Thesis. Indiana University of Pennsylvania, Indiana, PA.

Alqahtani, M. (2011). An investigation into the language needs of Saudi students studying in British postgraduate programs and the cultural differences impacting on them (Doctoral Dissertation). University of Southampton: Southampton, UK.

Al-Qahtani, M. F. (2013). Relationship between English language, learning strategies, attitudes, motivation, and students' academic achievement. Education in Medicine Journal, 5(3), 19-29. http://dx.doi.org/10.5959/eimj.v5i3.124

Alrabai, F. (2011). Do motivational strategies work? An empirical investigation of the effectiveness of motivational strategies in foreign language classes. Saarbrücken, Germany: Lambert Academic Press.

Alrabai, F. (2014a). A Model of Foreign Language Anxiety in the Saudi EFL Context. English Language Teaching, 7(7), 82-101. http://dx.doi.org/10.5539/elt.v7n7p82

Alrabai, F. (2014b). Motivational practices in English as a foreign language classes in Saudi Arabia: Teachers 
beliefs and learners perceptions. Arab World English Journal, 5(1), 224-246.

Alrabai, F. (2014c). The effects of teachers' in-class motivational intervention on learners' EFL achievement. Applied Linguistics, 1-28. http://dx.doi.org/10.1093/applin/amu021

Alrabai, F. (2014d). Reducing language anxiety \& promoting learner motivation: A practical guide for teachers of English as a foreign language. Raleigh, NC: Lulu publishing company.

Alrabai, F. (2015). The influence of teachers' anxietyreducing strategies on learners' foreign language anxiety. Innovation in Language Learning and Teaching, 9(2), 163-190. http://dx.doi.org/10.1080/17501229.2014.890203

Alrahaili, M. (2013). Predictors of L2 attitudes and motivational intensity: A cross-sectional study in the Saudi EFL context ( $\mathrm{PhD}$ Thesis). The University of Newcastle, Callaghan, Australia.

Alrasheed, S. (2012). Exploring the nature of the Saudi English teachers' beliefs and attitudes towards EFL and its effects on their teaching practice. Paper Presented at the Saudi Scientific International Conference, London, England.

Alrashidi, O., \& Phan, H. (2015). Education context and English Teaching and learning in the Kingdom of Saudi Arabia: An overview. English Language Teaching, 8(25), 33-44. http://dx.doi.org/10.5539/elt.v8n5p33

Al-Saadat, A. E., \& Al-Braik, M. S. (2004). Assessing the roles of teachers and supervisors of English as a foreign language in the reform of English language curriculum in Saudi Arabia. Scientific Journal of King Faisal University, 5, 197-214.

Alsamadani, A., \& Ibnian, S. (2015). The relationship between Saudi EFL students' attitudes towards learning English and their academic achievement. International Journal of Education and Social Science, 2, 92-102.

Al-Saraj, T. M. (2014). Foreign language anxiety in female Arabs learning English: Case studies. Innovation in Language Learning and Teaching, 8(3), 257-278. http://dx.doi.org/10.1080/17501229.2013.837911

Al-Seghayer, K. (2014). The four most common constraints affecting English teaching in Saudi Arabia. International Journal of English Linguistics, 4(3), 17-26. http://dx.doi.org/10.5539/ijel.v4n5p17

Al-Shabbi, A. (1989). An investigation study of the practical preparation in EFL teacher preparation programmes in colleges of education in the Saudi Arabia. PhD Thesis. University of Wales, Cardiff, Wales.

Alshahrani, M., \& Alandal, A. (2015). An investigation of anxiety among elementary school students towards foreign language learning. Studies in Literature and Language, 11(3), 29-40.

Alshammari, M. M. (2011). The use of the mother tongue in Saudi EFL classrooms. Journal of International Educational Research, 7(4), 95-102. http://dx.doi.org/10.19030/jier.v7i4.6055

Al-Subahi, A. (1991). Teaching English in the Gulf (Saudi Arabia). Jeddah: Dar Al Funoon Printing Press.

Al-Zarah, L. N. (2008). An investigative study of the female initial teacher preparation programme in Saudi Arabia in an Islamic context: Perceptions of the key participants. Doctoral Dissertation. University of Durham, Durham, UK.

Baghdadi, A. (1985). The educational start in the Kingdom of Saudi Arabia, 1. Jeddah: Ashuruq Publishing House.

Bahanshal, D. (2013). The effect of large classes on English Teaching and learning in Saudi secondary schools. English Language Teaching, 6(11), 49-59. http://dx.doi.org/10.5539/elt.v6n11p49

Bashehab, O. S., \& Buddhapriya, S. (2013). Status of knowledge based economy in the Kingdom of Saudi Arabia: an analysis. Journal of Social and Development Sciences, 4(6), 268-277.

Brewster, S., Davies, P., \& Rogers, M. (Eds.). (2014). Flying high for Saudi Arabia (pp. 1-6). London: Macmillan.

Brophy, J. (2004). Motivating students to learn (2nd ed.). London: Lawrence Erlbaum Associates.

Dörnyei, Z. (2001). Motivational strategies in the language classroom. Cambridge, UK: Cambridge University Press. http://dx.doi.org/10.1017/CBO9780511667343

Elyas, T. (2008). The attitude and the impact of American English as a global language within the Saudi education system. Novitas-Royal, 2(1), 28-48.

Elyas, T., \& Picard, M. (2010). Saudi Arabian educational history: Impacts on English language teaching. Education, Business and Society: Contemporary Middle Eastern Issues, 3(2), 136-145. 
http://dx.doi.org/10.1108/17537981011047961

Fareh, S. (2010). Challenges of teaching English in the Arab world: Why can't EFL programs deliver as expected? Procedia-Social and Behavioral Sciences, 2(2), 3600-3604. http://dx.doi.org/10.1016/j.sbspro.2010.03.559

Faruk, S. (2013). English language teaching in Saudi Arabia: A world system perspective. Scientific Bulletin of the Politehnica University of Timişoara Transactions on Modern Languages, 12(1), 73-80.

Faruk, S. (2014). Saudis' attitude towards English: trend and rationale. Professional Communication and Translation Studies, 7, 173-180.

Hagler, A. (2014). A study of attitudes toward western culture among Saudi university students. Learning and Teaching in Higher Education: Gulf Perspectives, 11(1), 1-14.

Hamouda, A. (2013). An exploration of causes of Saudi students' reluctance to participate in the English language classroom. International Journal of English Language Education, 1(1), 17-34.

Hashemi, M., \& Abbasi, M. (2013). The role of the teacher in alleviating anxiety in language classes. International Research Journal of Applied and Basic Sciences, 4(3), 640-646.

Ismail, N. M. (2015). EFL Saudi Students' Class Emotions and Their Contributions to Their English Achievement at Taif University. International Journal of Psychological Studies, 7(4), 19-42. http://dx.doi.org/10.5539/ijps.v7n4p19

Javid, C. Z. (2014). Measuring Language Anxiety in an EFL Context. Journal of Education and Practice, 5(25), 180-192.

Javid, C., \& Umer, M. (2014). Saudi EFL learners' writing problems: a move towards solution. Proceedings from GSE 2014: The Global Summit on Education, 4-5.

Khan, I. (2011). Learning difficulties in English: Diagnosis and pedagogy in Saudi Arabia. Educational Research, 2(7), 1248-1257.

Kondo, D. S., \& Ling, Y. Y. (2004). Strategies for coping with language anxiety: The case of students of English in Japan. ELT Journal, 58(3), 258-265. http://dx.doi.org/10.1093/elt/58.3.258

Lightbown, P. M., \& Spada, N. (2013). Oxford Handbooks for Language Teachers: How Languages Are Learned (4th ed.). Oxford: Oxford University Press.

Liton, H. A. (2013). EFL teachers' perceptions, evaluations and expectations about English language courses as EFL in Saudi universities. International Journal of Instruction, 6(2), 19-33.

Mahboob, A., \& Elyas, T. (2014). English in the Kingdom of Saudi Arabia. World Englishes, 33, 128-142. http://dx.doi.org/10.1111/weng.12073

Mohammed, A. (2015). EFL effective factors: Anxiety and motivation and their effect on Saudi College student's achievement. Arab World English Journal, 6, 201-218.

Morris, N. O. (2011). Using technology in the EFL classroom in Saudi Arabia. Master's Thesis. SIT Graduate Institute, Brattleboro, VT, USA.

Moskovsky, C., Alshahrani, M., Ratcheva, S., \& Paolini, S. (2015). Aptitude as a predictor of second language achievement: an investigation in the Saudi Arabian context. Arab World English Journal, 6, 3-21.

Nagahashi, T. L. (2007). Techniques for reducing foreign language anxiety: Results of a successful intervention study. Retrieved from http://air.lib.akita-u.ac.jp/dspace/bitstream/10295/547/3/kk9-6.pdf

Niblock, T. (2006). Saudi Arabia: Power, legitimacy and survival. New York: Routledge.

Osailan, G. (2009). The English literacy experiences of advances Saudi EFL professionals in the United States. Doctoral Dissertation. Indiana University of Pennsylvania, Indiana, PA.

Oxford, R. L. (1990). Language Learning Strategies: What Every Teacher Should Know (1st ed.). Heinle ELT.

Rabab'ah, G. (2002). Communication problems facing Arab learners of English. Journal of Language and Learning, 3, 180-197.

Rabab'ah, G. (2005). Communication problems facing Arab learners of English. Grazer Linguistische Studien, 63, 63-75. Retrieved from http://search.proquest.com/docview/85634745?accountid=17227

Rahman, M., \& Alhaisoni, E. (2013). Teaching English in Saudi Arabia: Prospects and challenges. International, 
$4,112-118$.

Rajab, H. (2013). Developing speaking and writing skills of L1 Arabic EFL learners through teaching of IPA phonetic codes. Theory and Practice in Language Studies, 3, 653-659. http://dx.doi.org/10.4304/tpls.3.4.653-659

Richard, J. C., \& Rodgers, T. S. (2001). Approaches and methods in language teaching. New York, NY: Cambridge University Press. http://dx.doi.org/10.1017/CBO9780511667305

Salem, N. (2006). The role of motivation, gender and language learning strategies in EFL proficiency. Unpublished Master's thesis. The American University of Beirut, Beirut, Lebanon.

Shaikh, A. (1993). Methods of teaching English as a foreign language: a comparative study of traditional and modern approaches. Lahore, Pakistan: Carvan Book House.

Shawer, S. F. (2010). Classroom-level curriculum development: EFL teachers as curriculum-developers, curriculum-makers and curriculum-transmitters. Teaching and Teacher Education, 26, 173-184. http://dx.doi.org/10.1016/j.tate.2009.03.015

Syed, Z. (2003). The sociocultural context of English language teaching in the gulf. TESOL Quarterly, 37, 337-341. http://dx.doi.org/10.2307/3588508

Tallon, M. (2008). A culture of caring: Reducing anxiety and increasing engagement in first year foreign language courses. Paper Presented at the Collaborating for Student Success: Building Engagement in Learning. San Antonio, TX, University of the Incarnate Word.

Tanveer, M. (2007). Investigation of the factors that cause language anxiety for ESL/EFL learners in learning speaking skills and the influence it casts on communication in the target language. Master's Thesis. University of Glasgow, Glasgow, UK.

Taylor, C., \& Albasri, W. (2014). The impact of Saudi Arabia King Abdullah's scholarship program in the U.S. Open Journal of Social Sciences, 2, 109-118. http://dx.doi.org/10.4236/jss.2014.210013

Thaher, M. (2005). Communication apprehension among An- Najah National University students. An-Najah University Journal for Research-Humanities, 19, 627-678.

TOEFL $®$. (2009). The Official Guide to the TOEFL Test (3rd ed., pp. 428-436).

Tsiplakides, I., \& Keramida, A. (2009). Helping students overcome foreign language speaking anxiety in the English classroom: theoretical issues and practical recommendations. International Education Studies, 2, 39-44. http://dx.doi.org/10.5539/ies.v2n4p39

Wiseman, A. W. (2010). The uses of evidence for educational policymaking: global contexts and international trends. Review of Research in Education, 34, 1-24. http://dx.doi.org/10.3102/0091732X09350472

Zaid, M. A. (1993). Comprehensive analysis of the current system of teaching English as a foreign language in the Saudi Arabian intermediate schools. Unpublished Doctoral dissertation. University of Colorado at Boulder, Boulder, CO.

Note

Note 1. The grading system in Saudi Arabia universities is: $\mathrm{A}+($ Exceptional $)=95.00-100, \mathrm{~A}($ Excellent $)=$ $90.00-94.99, \mathrm{~B}+($ Superior $)=85.00-89.99, \mathrm{~B}($ Very Good $)=80.00-84.99, \mathrm{C}+($ Above Average $)=75.00$ $-79.99, \mathrm{C}(\mathrm{Good})=70.00-74.99, \mathrm{D}+($ High Pass $)=65.00-69.99, \mathrm{D}($ Pass $)=60.00-64.99, \mathrm{~F}($ Fail $)=$ $0.00-59.99$.

\section{Copyrights}

Copyright for this article is retained by the author(s), with first publication rights granted to the journal.

This is an open-access article distributed under the terms and conditions of the Creative Commons Attribution license (http://creativecommons.org/licenses/by/3.0/). 